\title{
AS TRANSFORMAÇÕES NO MUNDO DO TRABALHO E A QUESTÃO DA SAÚDE - ALGUMAS REFLEXÕES PRELIMINARES
}

Luciane Prado Kantorski *

KANTORSKI, L.P. As transformações no mundo do trabalho e a questão da saúde - algumas reflexões preliminares.

Rev.latino-am.enfermagem, Ribeirão Preto, v. 5, n. 2, p. 5-15, abril 1997.

Neste artigo realizo algumas reflexões preliminares sobre as transformações no mundo do trabalho e a saúde. Para isto inicio o estudo colocando algumas dimensões essenciais do trabalho como categoria central para analisar a sociedade, a partir da concepção marxista. A seguir resgato nas transformações do mundo do trabalho a especificidade da saúde refletindo sobre a questão do cuidado e da organização dos trabalhadores de saúde.

\section{UNITERMOS: transformações, mundo do trabalho, saúde}

No presente estudo me proponho a refletir sobre as transformações que têm ocorrido no mundo trabalho, tomando o trabalho como categoria central. No espaço deste texto procuro discutir a centralidade do trabalho para entendimento da sociedade, desenvolver brevemente o conteúdo e a complexidade das transformações no mundo do trabalho e buscar uma aproximação destas reflexões à especificidade da saúde. A partir disto aponto ao menos duas preocupações que, a meu ver, são fundamentais na reflexão do trabalho na área da saúde, a saber: a questão do cuidado e da organização dos trabalhadores de saúde.

\section{A CENTRALIDADE DA CATEGORIA TRABALHO}

Para pensar os diversos modos como o homem vem se constituindo, objetiva e subjetivamente na vida, considero que o trabalho seja uma categoria central. A fim de resgatar a importância do trabalho na vida do homem destaco a princípio cinco dimensões essenciais que traduzem mais claramente esta importância.

Primeira: o homem ao produzir a sua própria existência produz a si mesmo. Isso significa que o trabalho consiste em uma condição inexorável da existência humana, pois observa-se ao longo de milhões de anos, que o trabalho foi o meio pelo qual o homem se diferenciou da sua condição de animal e constituiu-se como ser humano. $\mathrm{O}$ trabalho tem um papel fundamental no processo antropogenético da existência humana, deste modo, não se pode falar em ser humano desvinculando-o da sua atividade material transformadora.
MENDES GONÇALVES ${ }^{15}$ (1990) ao abordar as práticas de saúde tendo como eixo o processo de trabalho e as necessidades desenvolve mais aprofundadamente esta compreensão marxista e reafirma o fato de o homem (diferente dos outros animais) elaborar na sua mente a execução de algum trabalho antes de transformá-lo em realidade, ou seja, a teleologia humana, o trabalho dotado de finalidade.

Ao olhar para o processo de trabalho em saúde é preciso fazer algumas considerações. Como afirma MENDES GONÇALVES ${ }^{15}$ (1990) o trabalho em saúde não pode ser tomado como mercadoria de forma imediata, pois não produz bens materiais imediatos que servem como meio de produção de mais-valia e acumulação de capital. Entretanto, o trabalho em saúde produz resultados que correspondem à reprodução das necessidades do homem. Tais necessidades são sócio-historicamente determinadas e exigem acúmulo de saberes capazes de fazer a sociedade mudar enquanto se reproduz. Evidencio como exemplo desse processo o período de transição para o capitalismo. Na ocasião torna-se necessária a construção de uma nova racionalidade médica que acaba por constituir novas necessidades sociais, o processo tem como eixo o novo significado social dos corpos humanos enquanto força de trabalho e os princípios políticoideológicos - como a igualdade - capazes de dar estabilidade à estrutura capitalista emergente. Assim o trabalho em saúde passa a visar ao controle, em escala social mais ampla, da doença - que adquire um significado de incapacitação para o trabalho -, à recuperação da força de trabalho e à ampliação da capacidade de consumo e dos direitos das classes mais desfavorecidas.

* Professora Assistente da Faculdade de Enfermagem e Obstetrícia da Universidade Federal de Pelotas (UFPEL) e doutoranda do Programa Interunidades de Doutoramento em Enfermagem - USP - Ribeirão Preto 
A discussão acima demonstra como o homem ao produzir a sua própria existência, através do trabalho, constitui formas de sociabilidade, modos de pensar e intervir no processo saúde-doença e necessidades sociais para sua própria reprodução enquanto ser humano.

Segunda: a práxis do trabalho revela uma relação metabólica entre o homem e a natureza. $\mathrm{O}$ homem ao trabalhar transforma a natureza de acordo com um projeto construído conscientemente, no entanto, o homem ao mesmo tempo é também transformado pela natureza. Assim a soberania do homem diante do real é relativizada, já que ao transformar a natureza é também transformado por ela, numa relação que para o homem é obrigatória, se deseja sua sobrevivência.

NETTO $^{16}(1986$, p. 28$)$ ao abordar o pensamento marxiano enfatiza que Marx:

\section{“... concebeu o homem como um ser prático e social, produzindo a si mesmo através de suas objetivações (a práxis, de que o processo de trabalho é um momento privilegiado) e organizando as suas relações com os outros homens e com a natureza conforme o nível de desenvolvimento dos meios pelos quais se mantém e se reproduz enquanto homem".}

Em relação a esta dupla transformação que ocorre entre homem e natureza mediada pelo trabalho dotado de finalidade, Marx desenvolve a compreensão de que ao se relacionar socialmente pelo trabalho o homem também é transformado pelas relações e múltiplas determinações que nesse processo se estabelecem.

“... na produção social da própria existência, os homens entram em relações sociais determinadas, necessárias, independentes de sua vontade; estas relações de produção correspondem a um grau determinado de desenvolvimento de suas forças produtivas materiais... $O$ modo de produção da vida material condiciona o processo de vida social, política e intelectual” (MARX ${ }^{13}, 1992, \mathrm{p}$. 82).
Terceira: o trabalho gera relações sociais. Ao garantir os meios necessários a sua sobrevivência através do trabalho o homem estabelece relações sociais com outros homens. O trabalho sempre significou a convivência coletiva e evoluiu por diversos estágios de divisão que marcaram diferentes épocas. São estas relações sociais de produção que geram as possibilidades de troca, de compartilhamento de desejos e projetos entre os homens.

ENGELS $^{3}$ em sua obra A origem da família, da propriedade privada e do Estado utiliza-se dos estudos de Morgan sobre comunidades primitivas para demonstrar que no desenvolvimento da história humana a ampliação de fontes de existência ${ }^{1}$, de domínio do homem sobre a natureza guarda relação com os diferentes estágios de organização e divisão do trabalho, representando formas diferentes de propriedade, de constituição da família e do Estado.

MARX \& ENGELS ${ }^{14}$ (1989) ao retomarem esta questão da divisão do trabalho e da propriedade vão delimitar três formas de propriedade. A primeira é a propriedade tribal, que corresponde ao estágio mais rudimentar da produção, onde as atividades são a caça, pesca e eventualmente a agricultura. Nesta fase a divisão do trabalho é pouco desenvolvida e vai representar uma espécie de extensão da divisão familiar. A segunda forma é a propriedade comunal e propriedade do Estado, presente na Antiguidade, onde várias tribos se reúnem numa cidade (por conquista ou contrato). Aqui está presente a escravidão, já se desenvolve a propriedade privada e a divisão do trabalho já está mais avançada encontrandose oposição entre cidade e campo e mais tarde entre os estados que representam interesses das cidades ou dos campos. A terceira é a propriedade feudal, com expansão da propriedade privada a partir do campo. A divisão do trabalho, segundo os autores, pouco se desenvolveu no apogeu do feudalismo, estando presente a oposição campo/cidade, a divisão em estamentos era acentuada, mas a divisão do trabalho não era significativa.

Com relação à saúde-doença ressalto que a doença na sociedade primitiva era vista como uma entidade que se apossava do indivíduo causando-lhe sofrimento, cabendo ao xamã apropriar-se da entidade doença e expulsá-la, baseado no pensamento mágico e

\footnotetext{
${ }^{1}$ A classificação de Morgan, utilizada por ENGELS3 consiste em: “...Estado selvagem - Período em que predomina a apropriação de produtos da natureza, prontos para ser utilizados; as produções artificiais do homem são, sobretudo, destinadas a facilitar esta apropriação. Barbárie - período em que aparecem a criação de gado e a agricultura, e se aprende a incrementar a produção da natureza por meio do trabalho humano. Civilização - período em que o homem continua aprendendo a elaborar os produtos naturais, período da indústria propriamente dita e da arte” (p. 25).

A seguir ENGELS3 refere que: “... a civilização é o estágio de desenvolvimento da sociedade em que a divisão do trabalho, a troca entre indivíduos dela resultante, e a produção mercantil - que compreende uma e outra - atingem seu pleno desenvolvimento e ocasionam uma revolução em toda a sociedade anterior... A escravidão é a primeira forma de exploração, a forma típica da Antiguidade; sucedem-na a servidão na Idade Média e o trabalho assalariado nos tempos modernos” (p. 139-140).
} 
em atividades rituais, aceitos socialmente. No modelo grego da medicina hipocrática a doença era compreendida como um estado qualitativo de alteração da natureza que busca o reequilíbrio, instituindo no processo de trabalho da clínica a classificação e a observação. Na Idade Média a doença era tomada como uma provação a qual o homem tende a ser submetido para conquistar o paraíso e o trabalho médico tem um caráter expectante e passivo.

Quando a medicina moderna se constitui como prática social, no final do século XVIII, no interior do capitalismo, o que se observa é a predominância do modelo clínico, que entende a doença como uma alteração morfológica e/ou funcional sem dimensão ontológica. O processo de trabalho em saúde desempenhado no início unicamente pelo médico tem como local de trabalho o hospital moderno e o produto deste processo de trabalho passa a ser um bem consumível apenas individualmente (MENDES GONÇALVES ${ }^{15}$, 1990).

Deste modo reitero que o trabalho gera relações sociais que vão sendo construídas dinamicamente, a partir da inserção dos homens no processo de trabalho gerado na sociedade que se constituí em diferentes épocas. Os modos como se constrói a cultura, o saber, os olhares sobre a saúde-doença e as formas de intervir neste processo estão dialeticamente relacionados com os modos como o homem produz sua própria existência e se constitui histórica e socialmente.

Quarta: $O$ trabalho é fundamental para a criação da identidade do homem. Ao trabalhar o homem deixa a sua face na natureza, reconhece a si mesmo e produz sua identidade social. Ao criar o novo, através da práxis do trabalho - enquanto resultante de um projeto idealmente concebido (subjetivamente), que se materializa (objetivamente) na natureza - o homem se diferencia de outros homens, ao mesmo tempo se afirmando enquanto ser histórico e social.

LUKÁCS ${ }^{10}$ ao refletir sobre a ontologia marxiana do ser social, fundada no significado do trabalho na vida dos homens refere que:

“... o ser social em seu conjunto e em cada um de seus processos singulares pressupõe o ser da natureza inorgânica e orgânica. Não se pode considerar o ser social independente do ser da natureza... As formas de objetividade do ser social se desenvolvem, à medida que surge e que se explicita a práxis social, a partir do ser natural para depois se tornarem cada vez mais declaradamente sociais... $O$ processo histórico de sua explicitação, todavia, implica na importantíssima transformação do ser em-si num ser parasi e, por conseguinte implica na superação tendencial das formas e dos conteúdos de ser meramente naturais em formas e conteúdos sociais mais puros, mais especificamente sociais" (1981, p.93).

Quinta: $O$ trabalho, enquanto práxis propriamente humana é a maneira pela qual o homem transcende-se no espaço e no tempo, pois através do trabalho o homem imprime no mundo material um conhecimento acumulado ao longo da história, constituindo-se assim produtor de sua própria história.

Entendo que o momento do trabalho é veiculador de cultura, transmitida de geração para geração e que este expressa o desenvolvimento do saber humano sobre a realidade que se modifica ao longo do espaço e do tempo. Desta forma é que o homem se pereniza no tempo colocando sua identidade no produto do trabalho, situandose no espaço da produção e constituindo-se, assim, sujeito coletivo de seu próprio projeto existencial.

Ao trazer essa abstração para o trabalho em saúde mental, destaco por exemplo que o louco tem sido olhado e tratado historicamente de formas bastante diversas. Desde que a loucura vagava livre pelos campos, pois os feudos eram praticamente auto-suficientes e as características do trabalho rural suportavam a convivência com a maioria dos diferentes, até o advento da psiquiátrica e do hospital psiquiátrico muitas formas de interagir com o louco foram se constituindo. A loucura vista como manifestação da natureza, de exaltação, demoníaca, de paixões, devaneios, a loucura confinada nos porões das Santas Casas - onde os loucos eram depositados, sem finalidade terapêutica, apenas objetivando a limpeza das cidades que emergiam -, o trabalho fabril que exigia novas habilidades, qualificações e atividades repetitivas que não comportavam as manifestações da loucura. Entendimentos diversos acerca da loucura que foram se constituindo desde a Antigüidade até o presente, demonstram que através da práxis do trabalho - dos modos como o homem produz sua existência e se reproduz socialmente - o homem constrói a sua própria história. Ressalto que o modo de produção da vida material mantém relação com a cultura dos diversos grupos, os saberes e práticas de que cada sociedade, em cada época, se utiliza para designar os seus loucos e definir o que fazer com eles.

A construção desta história diz respeito aos homens imprimindo no mundo material conhecimentos acumulados ao longo das civilizações, diz respeito ainda à disputa de espaços, a determinações estruturais e superestruturais, aos conflitos que dão continuidade ou possibilitam a ruptura, em cada sociedade em particular.

MARCUSE $^{12}$ (1978) faz algumas reflexões sobre o trabalho enquanto portador de dimensões essenciais para o projeto civilizatório do homem. $\mathrm{O}$ autor 
considera que o trabalho é mais que um meio de conservação da vida humana, concebendo-o como meio de desenvolvimento da natureza universal do homem. Enfatiza, no entanto que na sociedade moderna a forma de trabalho que se constituiu remete para uma alienação total do homem. Resgata em Marx que a divisão do trabalho não guarda relação com as aptidões individuais ou interesses gerais, sendo colocada estritamente por leis capitalistas de produção.

O conceito de alienação reportado a Marx é exemplificado através da relação do trabalhador com o produto do seu trabalho e com sua própria atividade. $\mathrm{O}$ trabalhador ao trabalhar para o capitalista entrega a ele o produto do seu trabalho, que passa a ser para ele uma entidade alheia. A alienação do trabalhador do produto de seu trabalho vem a implicar, por sua vez, em uma alienação de si mesmo já que o trabalho não objetiva o desenvolvimento de potencialidades humanas, a satisfação e o prazer. Passa sim a significar, de forma negativa, um meio para satisfazer as necessidades de sobrevivência e consumo. Necessidades estas que passam a ser concebidas como exteriores ao próprio trabalho. As próprias relações que se estabelecem no momento do trabalho aparecem reificadas, ou seja, não aparecem como relações sociais entre os indivíduos que trabalham, mas como relações de trocas materiais entre pessoas (MARCUSE $^{12}$, 1978).

\section{O CONTEÚDO E A COMPLEXIDADE DAS TRANSFORMAÇÕES NO MUNDO DO TRABALHO}

Partindo do entendimento de que o trabalhoé uma categoria central para pensar a sociedade capitalista, retomo as especificidades das transformações ocorridas no mundo do trabalho ao longo da história, a partir das designadas revoluções industriais.

Considero que a Revolução Industrial, ocorrida no século XVIII (iniciada na Inglaterra), foi essencialmente uma revolução social porque, além da evolução da tecnologia ${ }^{2}$, significou o surgimento de novas classes sociais antagônicas - a burguesia e o proletariado e a passagem da sociedade agrária para a industrial. Esta, trouxe profundas mudanças, políticas e sociais, e significou uma grande mudança no processo de trabalho, não só pela introdução de uma base técnica, como pela função do trabalho assalariado.
$\mathrm{Na}$ saúde muitas mudanças também se processaram. Com o aumento da concentração de pessoas nas cidades, também o perfil nosológico da população se altera e aumentam os casos de doenças infecto-contagiosas ligadas às condições sanitárias. Ocorre também uma transformação do hospital que, no período feudal, caracterizava-se como instituição de caridade destinada a abrigar pobres, velhos, loucos, entre outros, passando então a constituir-se como espaço de cura e estudo das doenças. Com os adventos da anatomia, fisiologia, do microscópio, da histologia, da bacteriologia, novos saberes, novos instrumentos foram transformando o processo de trabalho em saúde. O mesmo passa a assumir uma função importante de manutenção e reprodução da força de trabalho a ser utilizada na indústria e portanto na consolidação do capitalismo. Neste processo de trabalho que tem como local de exercício o hospital moderno, a medicina enquanto uma prática social tida milenarmente como "autônoma" apresenta-se como responsável pelo diagnóstico e pela terapêutica e a enfermagem surge no campo das profissões-ocupações paramédicas, como prática assalariada e submetida no interior do processo de trabalho à prática médica.

A divisão social do trabalho que ocorre reproduz em parte a divisão em classes sociais dada no âmbito mais geral da sociedade capitalista e tem determinado na área da saúde uma divisão técnica que se configura em um acentuado parcelamento do trabalho em saúde e em categorias de trabalhadores com funções, habilidades, qualificações, remuneração e status extremamente diversificados

A chamada Segunda Revolução Industrial (iniciada nos EUA) também não se caracterizou somente por mudanças na base técnica ${ }^{3}$ e, sim, por mudanças sociais decorrentes de uma nova organização capitalista. O capitalismo liberal é substituído pelos monopólios, ocorre um aumento no número de assalariados e instala-se a produção em massa. A preocupação consiste na racionalização do trabalho e com Taylor se concretiza frente à proposta de execução de tarefas de acordo com tempos e movimentos previamente estabelecidos e controlados por uma gerência. Ford estende as inovações tayloristas quando introduz as linhas de montagem, sendo que o tempo no processo de produção em série passa a ser imposto.

O processo baseado na produção em massa e no fordismo caracteriza-se pela rigidez, controle do trabalho, homogeneização, pressupondo a intensificação do consumo para manutenção de um determinado padrão

\footnotetext{
${ }^{2}$ A evolução da tecnologia aplicada à produção de mercadorias caracterizou-se principalmente pela utilização do ferro como matéria prima, pela substituição da energia humana pela energia a vapor e conseqüente expansão do mercado.

${ }^{3}$ Estas mudanças na base técnica caracterizam-se principalmente pela utilização do petróleo, passagem da energia a vapor para a energia elétrica, substituição do ferro pelo aço, desenvolvimento dos meios de transporte e de comunicação.
} 
de vida. Este contexto trouxe, sem dúvida, transformações à existência humana, ao modo de viver e compreender a vida, às formas de sentir este mundo do trabalho em que as exigências eram de outra ordem, absolutamente diferentes da sociedade agrária ou mesmo do início do processo de industrialização.

$\operatorname{GRAMSCI}^{7}$ (1984, p. 375), ao estudar o americanismo e o fordismo, reflete mais detalhadamente sobre essa passagem do velho individualismo econômico para a economia programática. $\mathrm{O}$ autor analisa alguns aspectos ${ }^{4}$ que deveriam dar sustentação a esta passagem e que consolidariam um novo homem em consonância com um novo mundo do trabalho e da produção.

Com relação ao trabalho em saúde podemos destacar algumas das influências tayloristas que contribuíram para o maior parcelamento do mesmo. Inicialmente com o avanço tecnológico crescente, muitas tarefas até então realizadas por médicos foram designadas à enfermagem, acentuando-se a divisão entre o trabalho intelectual (médico) e o trabalho manual (enfermagem). No interior da própria equipe de enfermagem esta questão se alterou pois a divisão anterior entre as nurses (cuidado direto) e as ladies-nurses (atividades de supervisão, administração e ensino) acentua-se, sendo a equipe cada vez mais estratificada em função da complexidade das tarefas a serem realizadas, da qualificação exigida, da hierarquia e da remuneração.

Os estudos de tempo e movimento utilizados para estabelecer padrões do trabalho nas fábricas foram utilizados, por exemplo, para organizar o trabalho em enfermagem, passando o mesmo a ser centrado em tarefas e procedimentos distribuídos conforme a competência e qualificação do pessoal, sob orientação dos princípios da gerência científica, em que o enfermeiro sustentou-se enquanto liderança da equipe de enfermagem. Ocorre um aumento de pessoal semitreinado e até não treinado nos hospitais, carecendo menor número de enfermeiros que passam a assumir funções mais administrativas. O cuidado direto é dividido em tarefas (por exemplo verificação de sinais vitais) desempenhadas por um único trabalhador a um grande número de pacientes, sendo o mesmo distribuído, supervisionado e disciplinado pelo enfermeiro.

JOFFELY $^{9}$ (1994) coloca que o Japão foi a sede impulsionadora da chamada Terceira Revolução
Industrial $^{5}$, na medida em que entre 1950 e 1970 a montadora Toyota promove uma adaptação e modificação do fordismo que proporcionou a criação de um novo sistema, o toyotismo. Esse autor reconhece que um instrumento tecnológico indispensável para esta modificação em curso tem sido o computador. Descreve ainda as características do toyotismo como: a produção ser flexível (são fabricados muitos modelos em pequena quantidade, sendo que a demanda determina a oferta), o trabalho ser polivalente (cada trabalhador da Toyota opera em média cinco máquinas, sendo que grupos pequenos de trabalhadores operam várias máquinas, fazem controle de qualidade, alguns serviços de manutenção) e a terceirização (cada empresa focaliza uma especialidade e é subcontratada pela Toyota, isso reduz custos com pessoal fixo, pois conforme o autor os salários são de $30 \%$ a $50 \%$ dos pagos pela Toyota).

Como consequiência das transformações no mundo do trabalho aponto a necessidade de destruir e reconstruir habilidades no trabalhador, o aumento do número de trabalhadores flexíveis ou não fixos, a diminuição dos trabalhadores com vínculo, o aumento do desemprego a nível mundial. Ainda o fato de o produto e o capital passarem a girar mais rapidamente em função da demanda e da flexibilização, e a ocorrência de um grande retrocesso do poder do movimento sindical.

É preciso assinalar que tais mudanças emergem em um contexto mundial em que após a Segunda Guerra passara-se por um longo período de crescimento econômico dos países industrializados (em que com a criação do euromercado em 1960-70 a economia passa a ser mais globalizada, o dinheiro tornando-se dinheiro mundial), seguindo-se a ele um período de crise nas taxas de crescimento durante o início dos anos 70. A crise de acumulação econômica acaba provocando uma crise de financiamento do Estado de Bem-Estar Social (TEIXEIRA $^{20}$, 1994).

Este contexto de crise somado à invasão da microeletrônica, da biotecnologia, traz consigo uma nova forma de sociabilidade regida pelo privatismo na qual a reprodução do capital passa a exigir novas formas de produção e de relações sociais, apoiadas, por exemplo, na necessidade do trabalhador de conservar o emprego e no desgaste das organizações representantes dos interesses dos trabalhadores. O ideário neoliberal dá

\footnotetext{
${ }^{4}$ Alguns destes aspectos seriam: a racionalização da composição demográfica européia em função do tipo humano e do modo de produzir baseado no fordismo (isso significa conciliar os benefícios do poder de concorrência do fordismo mesmo mantendo o exército de parasitas europeus), a questão sexual ( a preocupação das indústrias fordistas com as relações sexuais, a família, a adaptação psicofísica a determinadas condições de trabalho vinculada à concepção de que para desenvolver esse novo tipo humano é preciso também racionalizar e regular o instinto sexual). Assim Gramsci segue no decorrer do capítulo Americanismo e Fordismo a aprofundar esta análise do novo tipo humano no novo mundo de trabalho (GRAMSCI ${ }^{7}, 1984$ ).

${ }^{5}$ A Terceira Revolução Industrial consiste no processo de implantação e difusão de novas tecnologias como a eletrônica e as tecnologias de informação como a informática e a telemática.
} 
sustentação a esta nova forma de sociabilidade, pois se baseia na desregulação da economia, na globalização, na flexibilização do processo produtivo, na orientação do consumo qualificado baseado em nichos de mercado, na incorporação crescente de tecnologia e na retirada progressiva do Estado dos setores da esfera dos chamados direitos sociais, como é o caso da saúde, da educação, da previdência social.

Com relação a esta questão destaco as discussões que têm ocorrido no Brasil durante o processo de revisão Constitucional, acerca da previdência social onde a tônica vigente tem sido a privatização viabilizada por um sistema de capitalização de recursos e repartição destes funcionando desta forma para os assalariados com maior renda e estando sob o controle do setor privado e a criação de uma outra previdência para pobres, de poucos recursos e sob o controle do Estado (FALEIROS ${ }^{4}$, 1994).

No campo específico da saúde a situação em muito se aproxima, já que os avanços do movimento sanitário na busca de um sistema de saúde baseado na lógica da solidariedade e na responsabilidade do Estado, expandidos especialmente a partir da década de 80, diluemse muito frente às opções econômicas e políticas dos governos atuais.O abortamento do Sistema Único de Saúde (SUS), traduzido pela lentidão na sua regulamentação, pelos baixos recursos destinados ao setor, pela não implementação urgente do sistema, demonstra como as mudanças ocorridas na macro-estrutura que é redimensionadora do novo mundo do trabalho determinam a questão da saúde, inclusive limitando muitas das possibilidades de organização da resistência a tal situação.

Este consiste em apenas um exemplo das opções econômico-políticas que tem se dado em função da manutenção do capitalismo. As novas formas de trabalho, de relações sociais, de identidade humana produzem também novas subjetividades, novos modos de compreender a vida e de andar por ela. Saliento que são introduzidos fenômenos complexos nesta realidade como os diversos tipos de violência, de exercício de poder, de religiosidade, de modificação de valores, desejos, atos e afetos. Não é por acaso que se debatem os motivos de o SUS estar sendo sucateado quando cerca de 120 milhões de brasileiros necessitam dele. Ao mesmo tempo, não são incompreensíveis as dificuldades de articulação do movimento sanitário em torno de um sistema de saúde mais solidário, equiitativo e justo para todos os brasileiros.

É pertinente destacar algumas das dificuldades

com que têm se defrontado as organizações que representam os interesses dos trabalhadores tais como o movimento sindical, materializadas nas seguintes tendências:

\begin{abstract}
"Uma crescente individualização das relações de trabalho, deslocando o eixo das relações capital e trabalho da esfera nacional para os ramos da atividade econômica e destes para o universo micro, para o local de trabalho, para a empresa e, dentro desta, para uma relação cada vez mais individualizada... Uma fortíssima corrente no sentido de desregulamentar e flexibilizar ao limite $o$ mercado de trabalho, atingindo duramente conquistas históricas do movimento sindical que tem sido, até o presente, incapaz de impedir tais transformações... O esgotamento de modelos sindicais vigentes nos países avançados $^{6}$ que optaram, nessa última década, pelo sindicalismo de participação e que agora contabilizam prejuízos de brutal envergadura - dos quais o mais evidente é o desemprego estrutural que ameaça implodir os próprios sindicatos" (ANTUNES ${ }^{1}, 1995$,
\end{abstract} p. 65).

A presente discussão é importante porque auxilia a compreender porque os avanços das lutas trabalhistas e sociais (como o direito à carteira de trabalho, o FGTS, as conquistas nas leis que regem a aposentadoria, o direito à assistência à saúde universal e eqüitativo sob a responsabilidade do Estado, entre outros) adquiridos em décadas anteriores são questionados e até vistos, nos anos 90, como impeditivos às reformas do Estado, ao avanço da estabilização e até ao crescimento da economia. As próprias organizações representativas dos interesses dos trabalhadores não têm conseguido dar respostas a estas mudanças. As dificuldades apresentadas podem ser atribuídas a inúmeros fatores entre eles, a recente experiência democrática brasileira, a fragilidade de tais instituições, as limitações teórico-práticas e especialmente políticas que os movimentos de esquerda têm para acompanhar um processo dinâmico de mudanças, o

\footnotetext{
${ }^{6}$ Nessa questão ANTUNES ${ }^{1}$ (1995)se apóia nos estudos de Freyssinet (1993) que coloca como variantes de modelos sindicais mais conhecidas nos países avançados as seguintes: modelo anglo-saxão (similar ao norte-americano) caracterizado por um governo neoliberal e conservador que busca a eliminação dos sindicatos, pela redução de direitos e fragmentação das negociações), modelo alemão (baseado na mediação e negociação entre Estado, patrões e sindicato, apontando alguns ganhos na gestão das empresas) e modelo japonês (com o sindicalismo de empresa que em troca de algumas garantias e da estabilidade no emprego, o trabalhador adere ao projeto da empresa).
} 
crescente desemprego que tem resultado deste processo, o próprio privatismo que individualiza as relações sociais dificultando toda forma de resistência no mundo do trabalho.

Com base em tais reflexões se torna mais compreensível o crescente pessimismo dos trabalhadores de saúde que têm se debatido entre as constatações dos limites do modelo clínico, do modelo epidemiológico de intervenção no processo saúde-doença, a falência do sistema de saúde e os limites de articulação em torno de uma reforma sanitária. Entendo que fazer esta reflexão é importante na medida em que ela ilumina a trajetória, no sentido de se vislumbrarem possibilidades de entendimento, reorganização e resistência ao concreto que hoje se apresenta desta forma.

Considero que o desemprego estrutural ${ }^{7}$, que tem se instalado em todos os países, reflete uma tendência mundial vinculada às opções privatistas que têm significado, especialmente nos países periféricos como o Brasil, uma opção pela estabilização inflacionária que advoga um crescimento mas não prioriza políticas de distribuição de renda ${ }^{8}$ por exemplo. No entanto o que se percebe é que esta tendência do capitalismo de globalização da economia é mundial e tem se dado, guardadas as especificidades tanto nos países centrais como periféricos.

ANTUNES $^{1}$ (1995) ao abordar a questão da subproletarização do trabalho frente à opção por formas de trabalho temporário, parcial $^{9}$, subcontratado e terceirizado exemplifica através dos estudos de BIRH (1990) a redução de empregos de tempo completo na França em 501 mil e um aumento de 111 mil de empregos de tempo parcial, entre 1982 e 1988.

A diminuição de empregos permanentes e o aumento do setor de serviços que compõem as mudanças no trabalho remetem para uma outra questão que é a da requalificação do trabalho. ANTUNES $^{1}$ (1995) afirma que a maior qualificação exigida dos trabalhadores frente à tecnologia e à polivalência é discutível visto que isto se diferencia entre os setores de trabalho ${ }^{10}$. Acrescenta que juntamente com esta uma outra tendência se desenvolveu, ou seja, ocorreu uma desqualificação de vários setores como os operários industriais gerados no fordismo e uma outra gama de trabalhadores da economia informal que oscila entre temporários, parciais, subcontratados, terceirizados (mesmo com a ressalva da existência de setores altamente qualificados que foram terceirizados) e também desempregados.

Evidencio a relevância do fenômeno da terceirização expandindo-se crescentemente obedecendo assim a uma tendência mundial, sem conseguir no entanto absorver a gama de desempregados existentes. Observo que atualmente nas universidades, hospitais e outros serviços de saúde cada vez mais alguns serviços - como limpeza, alimentação, informatização dos serviços, setores em que predomina a alta tecnologia complementar diagnóstica ou de tratamento, entre outros - têm sido terceirizados. Isso acarreta uma diminuição de postos fixos de trabalho e na necessidade de requalificação do trabalhador a partir das exigências de cada oportunidade de emprego.

Ainda sobre a introdução de novas tecnologias considero importante relatar que observei em uma macroestrutura psiquiátrica, onde acompanhei a progressiva informatização ${ }^{11}$ dos serviços, com a criação de um núcleo de pesquisa em saúde mental e informática, que tal fato não implica necessariamente em ampliação de autonomia relativa do usuário e melhoria das perspectivas de ressocialização. Os programas parcialmente ou em vias de implantação na referida instituição estão relacionados à constituição de um banco de dados de abrangência inicialmente municipal, à avaliação epidemiológica da introdução de um recurso terapêutico - a penicilina na neurossífilis -, à avaliação, gerenciamento e controle de

${ }^{7}$ Conforme dados do Fórum Econômico de Davos - Suíça, existem mais de 800 milhões de pessoas em todo o mundo que estão desempregadas ou subempregadas, este número equivale a treze vezes a população brasileira economicamente ativa, calculada em 60 milhões. Segundo o DIEESE 1,07 milhão de pessoas estão desempregadas somente na Grande São Paulo. O economista Mário Pochamann (UNICAMP) afirma que entre 1993 e 1995 a atividade econômica brasileira cresceu cerca de $15 \%$ e o número de empregos aumentou apenas $2 \%$ (FOLHA DE SÃO PAULO ${ }^{6}, 1996$ ).

${ }^{8}$ Em pesquisa realizada pelo Data Folha realizada nos dias 21 e 22 de agosto de 1995 São Paulo conta com 4549 pessoas que moram nas ruas, sendo que 38\% deles surgiram após a implantação do plano real (FOLHA DE SÃO PAULO ${ }^{5}, 1995$ ).

${ }^{9}$ ANTUNES $^{1}$ (1995) define aqui trabalho temporário como aquele onde o trabalhador não tem nenhuma garantia do emprego e trabalho parcial como aquele onde os trabalhadores são integrados precariamente às empresas.

10 ANTUNES $^{1}$ (1995) refere que ocorreu uma série de mudanças na classe trabalhadora, desqualificando-se em setores como mineração, metalurgia e construção naval, quase desaparecendo em setores que foram informatizados inteiramente e requalificandose como na siderurgia, com o surgimento dos operários-técnicos que têm atribuições de maior responsabilidade no processo de produção.

${ }^{11}$ Gostaria de evidenciar que com isto não estou advogando que a tecnologia é desnecessária, nem tão pouco que seja também desnecessária a introdução da informática nos serviços de saúde. Ao contrário acredito que este possa ser um recurso importante e útil (Ver ROCHA; FABBRO ${ }^{18}$, 1995). Estou sim questionando em que medida estas transformações implicam em maior qualidade de vida tanto para os trabalhadores de saúde como para os usuários dos serviços. 
qualidade $^{12}$ nos serviços de saúde mental, ao desenvolvimento e validação de indicadores de qualidade de assistência hospitalar.

Considero estes recursos extremamente importantes na organização e controle de serviços em saúde mental, embora entendo que a lógica empresarial que tem como princípio as necessidades da empresa ou instituição em relação ao que o processo produtivo requer - não é a mais adequada às questões de saúde, pois se o eixo da assistência for o usuário dos serviços suas necessidades é que deveriam ser colocadas como prioritárias.

O questionamento que faço não diz respeito à validade da informatização e dos dados epidemiológicos para o setor saúde. Aponto que embora o recurso da tecnologia seja tomado, de modo enviesado, como se fosse o grande boom que pode orientar o desenho do sistema de saúde, ele tem limitações, podendo e tendo sido usado para angariar recursos públicos aos hospitais psiquiátricos públicos ou privados, para dar sustentação ao modelo manicomial, para exercer maior controle sobre o trabalhador de saúde, entre outros. Evidencio que vivemos num tempo histórico em que se reconhece a falência terapêutica da estrutura manicomial, em que novos trabalhos em saúde mental baseados na desinstitucionalização passam a orientar as inovações na área, em que as possibilidades de ressocialização do indivíduo que padece de sofrimento psíquico são delimitadas a partir do território, da família, da comunidade onde vive. A crítica que aponto é o fato de tais tecnologias serem usadas para dar sustentação a um modelo manicomial extremamente segregador e excludente, ao mesmo tempo adequado às necessidades de reprodução capitalista, já que o louco considerado incapaz de ingressar no processo produtivo compõe uma gama de excluídos que carecem ser afastados dos olhos do restante da sociedade.

PIRES $^{17}$ (1996) ressalta as contribuições que o computador tem trazido à psiquiatria, a partir da experiência de dois pesquisadores da Universidade Federal de Pernambuco, com a utilização de softwares que auxiliam no diagnóstico da depressão e esquizofrenia. Os programas são considerados como mais um instrumento para realização do diagnóstico, embora sejam alvo de alguns críticos que afirmam que isso: “mecanizaria a relação psiquiatra-paciente $e$ tenderia à unificação de tratamentos, desprezando o perfil psicológico e sociocultural do paciente" (PIRES $^{17}, 1996$, p. 74).
Considero que não se pode negar o avanço tecnológico, tampouco não utilizá-lo como mais um instrumento do trabalho em saúde, porém, é necessário refletir sobre o eixo estruturante deste trabalho a fim de delimitar que tipo de tecnologia é adequada ao seu desenvolvimento.

\section{REPENSANDO O TRABALHO EM SAÚDE TENDO COMO EIXO O CUIDADO E A ORGANIZAÇÃO DOS TRABALHADORES DE SAÚDE}

Vários aspectos merecem ser levados em conta para repensar o trabalho em saúde no interior do processo de desenvolvimento social no mundo, no entanto, procurei fazer alguns recortes que remetessem, como disse Gramsci, para o novo tipo humano que tem se constituído neste bojo. Neste sentido, para finalizar resgato duas preocupações fundamentais no exercício desta reflexão que são: a questão do cuidado e da capacidade de luta e organização dos trabalhadores.

Compreendo que o paradigma racional doença cura permeia as relações de trabalho na saúde. Esse paradigma concentra em si uma compreensão teóricoprática que sustenta um olhar para o indivíduo sob a ótica da sua doença, desvinculando-o de uma relação dinâmica com a natureza e com a sociedade, que lhe possibilita a condição de encontrar-se ou não saudável. Ao mesmo tempo, a reprodução do capital, as relações que se estabelecem no processo produtivo e as normas que regem o modo de vida na sociedade determinam a reprodução deste paradigma, pois o conhecimento produzido e o modo como ele é viabilizado na prática são absolutamente convergentes com os interesses de reprodução do capital. $\mathrm{O}$ que tem se observado historicamente é que o processo de trabalho em saúde pautado ideologicamente no referido paradigma tem possibilitado um avanço da alta tecnologia em saúde (como na área de transplantes, de reprodução assistida, de pesquisa genética, entre outras) sem, no entanto, optar por formas de conhecer os problemas básicos de saúde de cada território e propor uma intervenção mais adequada às necessidades de saúde dos diversos grupos.

As questões sociais no processo de trabalho em saúde são vistas, no máximo, como mais um componente, na lista das possíveis causas de doenças. Ainda que se reconheçam os limites impostos pelos determinantes

\footnotetext{
$12 \mathrm{O}$ entendimento de qualidade em que se apóiam os programas nesse serviço baseia-se no referencial da qualidade total que advém da administração empresarial que visa à otimização de recursos, obtendo mais impacto com menos recursos, traçando objetivos, ações, atribuindo responsabilidades, oferecendo treinamento, avaliando, analisando e premiando o desempenho - entre outros programas de informática aplicada a saúde mental.
} 
estruturais, que dizem respeito ao modo de produção capitalista de existência humana que vivenciamos, tornase fundamental reconhecer os espaços emancipatórios que se colocam na superestrutura - onde se produz a ideologia que acaba por cimentar a hegemonia exercida por uma classe social - a fim de produzir transformações culturais que permitam também a intervenção na estrutura de produção. Debruçar-se sobre lamentações reprodutivistas que deságuam no imobilismo, não recupera a força do sujeito social e seu potencial de mudança, nem contribui para a reforma do sistema de saúde ou para tornar as relações de trabalho menos alienadas e mais solidárias.

Este caminho da doença - cura, da onipotência virtual da técnica, da qualificação de alguns, que requer a desqualificação e a marginalização de tantos, tem nos conduzido a uma crescente desumanização das relações sociais de um modo geral. Esta desumanização se constitui através da alienação pois o homem não se reconhece mais no objeto que o seu trabalho produz, nem este trabalho contribui para o seu pleno desenvolvimento e a satisfação plena de suas necessidades.

Pautada em tais referenciais, coloco como fundamental retomar a humanização no processo de trabalho em saúde enquanto possibilidade de busca da emancipação do trabalho alienado. Por mais que as transformações tenham desumanizado o trabalho em saúde, ele ainda tem como objeto um ser humano, feito de corpo, ossos, músculos, desejos, sentimentos, afetos, subjetividades.

ROTELLI $^{19}$ et al. (1990, p. 33), ao se referirem à desinstitucionalização da doença mental retoma a questão do cuidado e afirma que este processo: “... é, sobretudo, um trabalho terapêutico voltado para a reconstituição de pessoas, enquanto pessoas que sofrem, como sujeitos. Talvez não se resolva por hora, não se cure agora, mas no entanto seguramente se cuida”.

Acredito que esse paradigma do cuidado possa oferecer outros óculos para olhar a questão da saúde possibilitando um reconhecimento do outro enquanto sujeito de projetos, interesses e carecimentos.

É necessário esclarecer que não estou apregoando que a humanização das relações sociais possam acontecer desvinculadas das determinações estruturais e que por si só possam transformar a sociedade. O que tento resgatar é o que já afirmava GRAMSCI $^{8}$ (1991) sobre a importância da luta político- ideológica - tanto quanto o é o controle das forças produtivas - para o projeto de transformação.

Embora reconheça que a estrutura de produção determina em parte a consciência dos homens, penso assim como GRAMSCI $^{8}$ (1991) haver a necessidade de a classe trabalhadora lutar pela realização de uma revolução cultural, que modifique as crenças das pessoas, sendo capaz de criar novas formas de perceber e entender a sociedade tão fortes e imperativas quanto o eram as anteriores.

Considero que o cuidado é um eixo sobre o qual se pode pensar em construir uma transformação cultural das relações sociais que se dão na realização do trabalho em saúde, modificando a prática vigente nos serviços de saúde.

Na minha concepção, esse paradigma do cuidado fundado em condições materiais de existência e de configuração do processo saúde-doença pode remeter para a essência do trabalho em saúde rumo à integralidade do sujeito. Uma integralidade que pressupõe o empenho dos trabalhadores de saúde e clientela em pensar a reelaboração conjunta do modelo assistencial. Como sugere CAMPOS ${ }^{2}$ (1992) um modelo assistencial baseado na acolhida e no responsabilizar-se pelos sujeitos, que tem como centro de necessidades a clientela e seus interesses e não o conforto e a comodidade dos trabalhadores de saúde, nem tampouco a rigidez da rede hierarquizada ou a reprodução do capital.

Desse modo, considero indissociável ao resgate da questão do cuidado materializado no trabalho em saúde um segundo aspecto que consiste na capacidade de luta e organização dos trabalhadores. Evidencio que é necessário recompor referências e iniciativas transformadoras que recuperem a ação e os objetivos coletivos, recriados pelo sujeito social. É preciso se ater ao fato de que a sociedade guarda em seu interior conflitos antagônicos não superados, devido à permanência da contradição fundamental entre capital e trabalho geradora de luta de classes.

Conforme enfatiza ANTUNES ${ }^{1}$ (1995) o capitalismo contemporâneo não foi capaz de eliminar as diversas formas de alienação, de estranhamento, pois este até acentuou-se com a eliminação explícita do despotismo no fordismo, para um envolvimento manipulatório no toyotismo. Isto significa que o estranhamento entendido como as barreiras sociais que impedem o desenvolvimento da individualidade em direção à omnilateralidade humana ${ }^{13}$, o capitalismo contemporâneo fez emergir ainda mais intensamente.

\footnotetext{
${ }^{13}$ MANACORDA $^{11}$ (1991, p. 81) ao trabalhar o conceito marxiano de omnilateralidade humana refere que esta significa: “... $a$ chegada histórica do homem a uma totalidade de capacidades produtivas e, ao mesmo tempo, a uma totalidade de capacidades de consumo e prazeres, em que se deve considerar sobretudo o gozo daqueles bens espirituais, além dos materiais, e dos quais o trabalhador tem estado excluído em conseqüência da divisão do trabalho”.
} 
Entendo que se tem pela frente uma tarefa árdua de organização da classe-que-vive-do-trabalho (expressão utilizada por ANTUNES $\left.{ }^{1}, 1995\right)$ e que deve cotidianamente constituir-se como sujeito, ampliando espaços para construir a transformação. Esta tarefa inclui a articulação de fóruns e mecanismos diversificados de resistência que estimulem a participação dos trabalhadores de saúde viabilizando a aquisição de ganhos, oportunidades, emancipação, humanização através do trabalho. Isto exige compreender as práticas de saúde como sociais, sujeitas a determinações históricas que estão colocadas em uma sociedade capitalista periférica, dependente, pós-industrial e regida pela tônica neoliberal. Pensar o processo de trabalho fora deste contexto constitui-se em uma elaboração estéril e idealista, que não aponta para uma prática totalizante e transformadora deste processo de trabalho tão criticado historicamente pelos próprios trabalhadores de saúde.

\section{THE TRANSFORMATIONS IN THE WORLD OF WORK AND HEALTH - SOME PRELIMINARY REFLECTIONS}

In this work, I make some preliminary reflections about the transformations in the world of work and health. For this purpose, I start this study discussing essential dimensions of the work like the central category to analyse the society based on the Marxist conception. Following, I investigate transformations in the world of work and the specificity of health to the related reflection about care and the organization of health workers.

KEY WORDS: transformations, world of work, health

\section{LAS TRANSFORMACIONES EN EL MUNDO DEL TRABAJO Y LA SALUD - ALGUNAS REFLEXIONES PRELIMINARES}

En este artículo realizo algunas reflexiones preliminares sobre las transformaciones en el mundo del trabajo y la salud. Para esto, inicio el estudio colocando algunas dimensiones esenciales del trabajo como categoría central, para analisar la sociedad, a partir de la concepción marxista. Enseguida rescato en las transformaciones del mundo del trabajo la especificidad de la salud trayendo para la reflexión el cuidado y la organización de los trabajadores de la salud.

TÉRMINOS CLAVES: transformaciones, mundo del trabajo, salud

\section{REFERÊNCIAS BIBLIOGRÁFICAS}

01. ANTUNES, R. Adeus ao trabalho ? : ensaio sobre as metamorfoses e a centralidade do mundo do trabalho. 2 ed. Campinas: Cortez, 1995.

02. CAMPOS, G. W. de S. Modelos de atenção em saúde pública: um modo mutante de fazer saúde. Saúde em Debate, Londrina, n. 37, p.16-19, dez. 1992.

03. ENGELS, F. A origem da família, da propriedade privada, e do Estado. In: MARX, K.; ENGELS, F. Obras escolhidas. São Paulo: Alfa-Omega, s.d. v. 3, p. 21-143.

04. FALEIROS, V. de P. Previdência social e neoliberalismo. Universidade e Sociedade, São Paulo, v. 4, n. 6, p. 87-93, fev. 1994.

05. FOLHA DE SÃO PAULO. São Paulo, 03 set. 1995. 06. . São Paulo, 03 mar. 1996.

07. GRAMSCI, A. Americanismo e fordismo. In: Maquiavel, a política e o Estado moderno. 5 ed. Rio de Janeiro: Civilização Brasileira, 1984. p. 375-413.

08. A concepção dialética da história. 9 ed. Rio de Janeiro: Civilização Brasileira, 1991.
09. JOFFELY, B. Uma revolução que desafia os sindicatos. Revista da CUT. v. 1, n. 2, p. 14-23, dez. 93/fev. 94.

10. LUKÁCS, G. A ontologia de Marx: questões metodológicas preliminares. In: LUKÁCS, G. Sociologia. São Paulo: Ática, 1981. p.85-108.

11. MANACORDA, M.A. Marx e a pedagogia moderna. São Paulo: Cortez, 1991.

12. MARCUSE, H. O advento da teoria social. In: Razão e revolução. 3 ed. Rio de Janeiro: Paz e Terra, 1978. p. 231-293.

13. MARX, K. O prefácio da contribuição à crítica da economia política. In: MARX, K. Sociologia. 7 ed. São Paulo: Ática, 1992. p. 82-83.

14. MARX, K.; ENGELS, F. A ideologia alemã. São Paulo: Martins Fontes, 1989.

15. MENDES GONÇALVES, R.B. Práticas de saúde: processos de trabalho e necessidades. Departamento de Medicina Preventiva da Faculdade de Medicina - USP. 1990. 94 p. / Mimeografado/

16. NETTO, J.P. O que é marxismo. 3 ed. São Paulo: Brasiliense, 1986. (Coleção Primeiros Passos, 148). 
17. PIRES, I. Computador auxilia a psiquiatria - softwares facilitam diagnóstico de distúrbios como depressão e esquizofrenia. Ciência Hoje, v. 20, n. 119, p. 74, abril 1996.

18. ROCHA, J. S. Y.; FABBRO, A. L. dal. Pelo reordenamento das práticas da saúde coletiva acerca da informatização da saúde. Saúde em Debate, n. 47, p. 23-27, jun. 1995.
19. ROTELLI, F.; LEONARDIS, O. de; MAURI, D.

Desinstitucionalização, uma outra via - a reforma psiquiátrica italiana no contexto da Europa Ocidental e dos "países avançados". In: ROTELLI,F.et al. (org). Desinstitucionalização. São Paulo: Hucitec, 1990. p. 17-59.

20. TEIXEIRA, F. J. S. Notas para uma crítica do fim da sociedade do trabalho. Universidade e Sociedade, v. 4, n. 6, p. 21-29, fev. 1994. 